\title{
Mechanism and Performance of Ammonia Removal with Novel Micro Electrolysis Filler in Wastewater
}

\author{
Guizhong Zhou ${ }^{1, a^{*}}$, QianYao ${ }^{1, b}$, Shuo XU ${ }^{1, c}$, Jianting Liu ${ }^{1, d}$,Dayi Zhang ${ }^{2, e}$ \\ ${ }^{1}$ College of Environment and Safety Engineering, Qingdao University of Science and Technology, \\ Qingdao, 266042, China \\ ${ }^{2}$ Lancaster Environment Centre, Lancaster University, Lancaster LA12YQ, UK \\ ${ }^{*}$ Corresponding author. \\ aemail: zhougz@lqust.edu.cn. eemail: d.zhang@lancaster.ac.uk.
}

\begin{abstract}
Keywords: Micro electrolysis filler, Ammonia, Removal Performance, Mechanism
Abstract. High ammonia wastewater, especially in the high chlorine wastewater, is difficult to treat in the field of wastewater treatment. Ammonia removal efficiency of porous iron carbon alloy filler in different factors and an in-depth research of $\mathrm{NH}_{3}-\mathrm{N}$ removal mechanism were studied in the paper. The experimental results showed that the iron carbon alloy filler of $\mathrm{NH}_{3}-\mathrm{N}$ had better removal effect. When the reaction time was $80 \mathrm{~min}$, the influent $\mathrm{pH}$ was 7 , influent $\mathrm{NH}_{3}-\mathrm{N}$ concentration was $600 \mathrm{mg} / \mathrm{L}$, and the reaction temperature was $45^{\circ} \mathrm{C}$, the $\mathrm{NH}_{3}-\mathrm{N}$ removal rate reached $35 \%$.
\end{abstract}

\section{Introduction}

Based on the many tiny primary battery reactions on the surface of electrodes, $\mathrm{Fe}-\mathrm{C}$ micro electrolysis was widely used on the pretreatment of hard biodegradable wastewater [1,2], but only few researchers committed to the research of ammonia removal. And most of the micro electrolysis filler used in some studies were simple mixture of iron grain and carbon particles which prone to harden and passivation in the actual treatment of wastewater, reducing the treatment efficiency. The filler in this paper have large specific surface area and high reaction activity which improve the reaction efficiency. It was pressed and roasted with iron, activated carbon powder and rare earth metal powder according to a certain proportion. Firstly, under this structure, iron and carbon are always one, not easy to separate. Secondly, the integration of iron and carbon in the galvanic reaction can reduce the resistance, thereby increasing electron transfer efficiency and improving processing efficiency. Finally, the architecture structure can avoid passivation of iron and carbon.

This paper mainly research into the influence of ammonium ions removal efficiency by changing the factors of initial $\mathrm{pH}$, temperature, reaction time, concentration of ammonium ions and organic matter content. Through intermittent experiment and continuous experiment to confirm the ammonium ions content in the respective reaction parts, further to determine the removal path and removal mechanism of ammonium ions.

\section{Experiments}

Materials preparation( Micro electrolysis filler): Granule diameter of less than 60 to iron, particle size of less than 100 to powdered activated carbon and rare earth metal powder as raw materials, including iron mass fraction of 5\% hydrochloric acid pickling solution for 20 min with scrap iron activation, according to the iron: powdered activated carbon: rare earth metal catalyst=85: (14.01 14.09): (0.91 0.99), under pressure 200kn pressed into the blank, and then isolated from the air in 1050 1200 ${ }^{\circ} \mathrm{C}$, heating 90 100min quenching of new iron carbon alloy micro electrolysis packing [3,4], as Fig1 shows. 


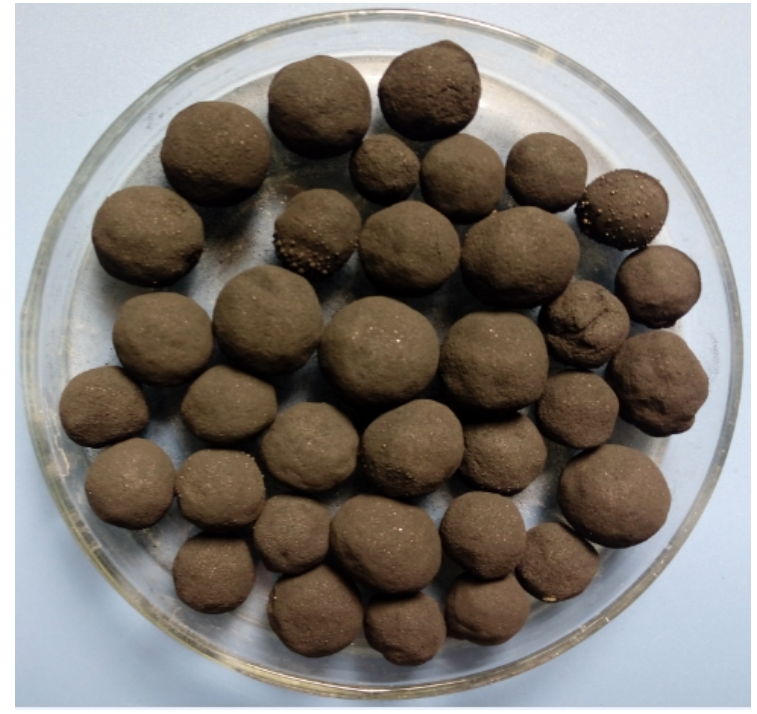

Fig. 1 Appearance of filler

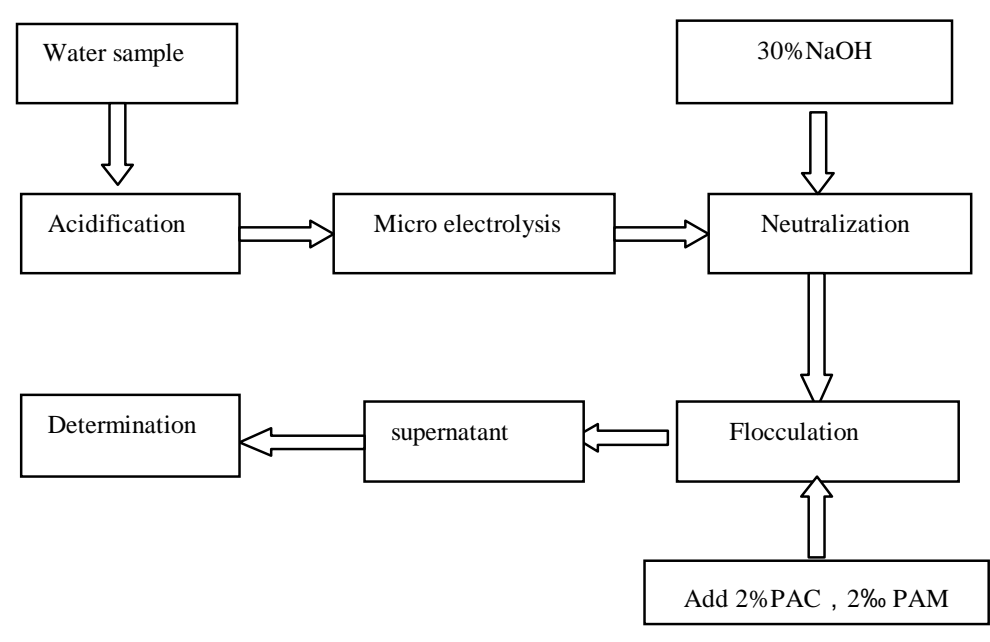

Fig.2 Reaction flow of micro electrolysis with iron carbon alloy

Experimental procedure: the process is shown in Fig. 2, wastewater with ammonia after adjusting $\mathrm{pH}$, by constant flow pump according to flow into the reactor, water enters from the bottom. At the same time the bottom aeration and iron carbon alloy filler is installed in the middle of the reactor, wastewater after reaction filler overflow to the sedimentation tank behind and waste water by micro electrolysis of $\mathrm{Fe}^{2+}$ and some organic matter in water has been destabilization, flocculation and sedimentation water clarification needs, therefore, adjusting the $\mathrm{pH}$ to about 9 , adding proper amount of $2 \%$ of the PAC and 2 per 1000 PAM flocculation and sedimentation, take supernatant determination of water quality index $[5,6,7]$. Continuous experiment is continuous inflow of water, with the flow control of residence time. Static experiment for the raw water directly into the reactor, the reaction time after a certain period of time will be released in the reactor water flocculation.

\section{Results and discussion}

Effect of reaction time on the removal of $\mathbf{N H}_{3}-\mathbf{N}$ : Preparation of ammonia nitrogen concentration is about $1500 \mathrm{mg} / \mathrm{L}$ ammonium sulfate solution $500 \mathrm{ml}$ for six copies, respectively, the added to the iron carbon alloy filler device, at room temperature (about $20{ }^{\circ} \mathrm{C}$ ) under the conditions of the experiment, respectively in $10 \mathrm{~min}, 20 \mathrm{~min}, 40 \mathrm{~min}, 60 \mathrm{~min}, 80 \mathrm{~min}, 100 \mathrm{~min}$ out $50 \mathrm{ml}$ water samples in six small beaker. The concentration of ammonia nitrogen was determined by flocculation after $\mathrm{pH}$ of water sample was 9 or so. The experimental data were processed and analyzed, and the results were obtained as Fig. 3 showed.

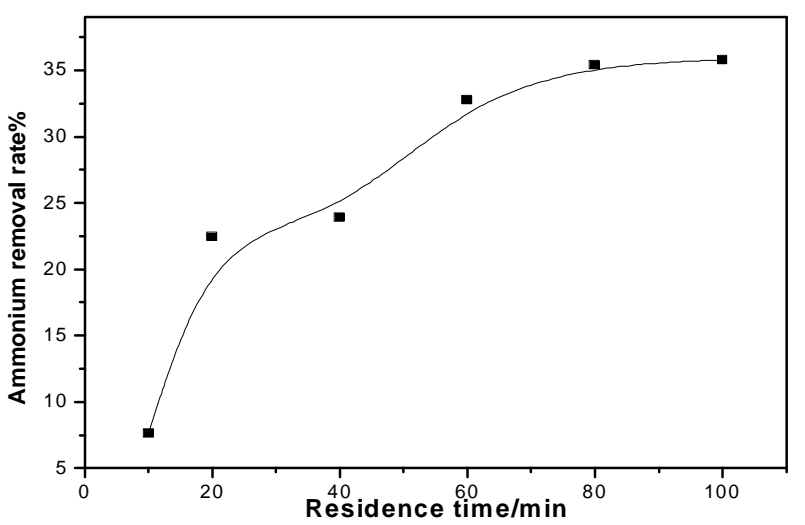

Fig.3 Effect of residence time on ammonium removal rate

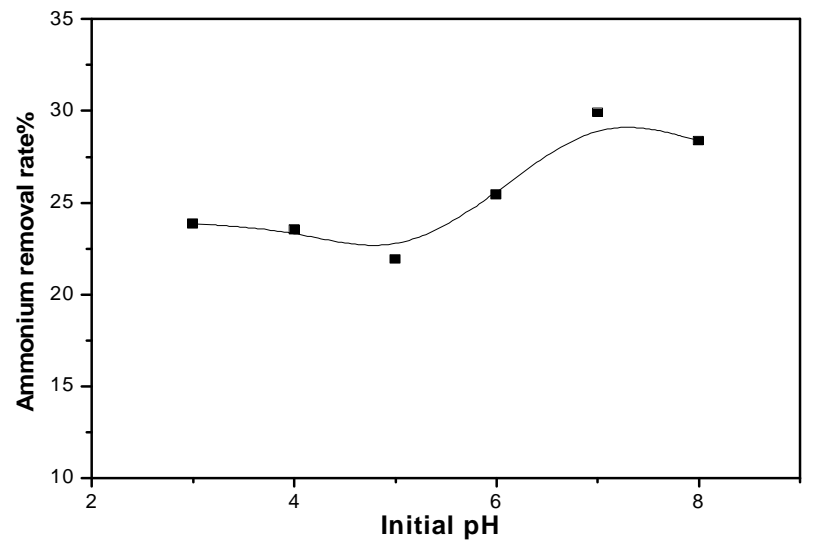

Fig.4 Effect of $\mathrm{pH}$ of initial reaction on ammonium removal rate 
With prolonged residence time, ammonia nitrogen removal rate of the general trend was rising; from $20 \mathrm{~min}$ to $30 \mathrm{~min}$, the removal rate of ammonia nitrogen varied greatly, and the stage, time variable effect on the dependent variable of ammonia nitrogen removal rate was very significant; and ammonium salt removal rate increased the amplitude was gradually reduced and when the residence time was over 80 , the removal rate of basic changes little. The best suitable time for the experiment of micro electrolysis treatment of high ammonia nitrogen was $80 \mathrm{~min}$.

Effect of pH on the removal of NH3-N: Preparation of ammonia nitrogen concentration was about $1500 \mathrm{mg} / \mathrm{L}$ ammonium sulfate solution $500 \mathrm{ml}$ six copies, with $30 \%$ sulfuric acid (or $30 \%$ sodium hydroxide solution to regulate $\mathrm{pH}$ respectively 3.0, 4.0, 5.0, 6.0, 7.0, 8.0, respectively were added into the iron carbon alloy reaction device, at room temperature (about $20{ }^{\circ} \mathrm{C}$ ) condition to continuous aeration experiment. Immediately stop aeration when the residence time was $80 \mathrm{~min}$, and $50 \mathrm{~mL}$ respectively from the device out of water in a small beaker. Then the $30 \%$ sulfuric acid solution (or $30 \%$ sodium hydroxide solution) were adjusted $\mathrm{pH}$ for about 9 , followed by flocculation experiments, and then the determination of ammonia concentration. By processing and analyzing the experimental data, the results were shown in fig. 4 .

The removal rate of ammonia nitrogen was slightly increased from 3 to 8 , but the effect was not significant. Comprehensive analysis, taking the initial reaction of $\mathrm{pH}$ is about 7 for the iron carbon micro electrolysis treatment of high ammonia nitrogen wastewater, the most suitable $\mathrm{pH}$ value.

Effect of influent $\mathbf{N H}_{3}-\mathbf{N}$ concentration on removal rate: Preparation of ammonia nitrogen concentrations were approximately $100 \mathrm{mg} / \mathrm{L}, 200 \mathrm{mg} / \mathrm{L}, 400 \mathrm{mg} / \mathrm{L}, 600 \mathrm{mg} / \mathrm{L}, 800 \mathrm{mg} / \mathrm{L}, 1000$ $\mathrm{mg} / \mathrm{L}$ ammonium sulfate solution $500 \mathrm{ml}$ six copies, with $30 \%$ sodium hydroxide solution to regulate $\mathrm{pH}$ was 7.0, then added to contain the quality ratio of six device with iron carbon fillers, at room temperature (about $20{ }^{\circ} \mathrm{C}$ ) under the condition of continuous aeration experiment. Immediately stop aeration when the residence time was $80 \mathrm{~min}$, and separately from the six device to remove $50 \mathrm{~mL}$ water in a small beaker. Then the $30 \%$ sulfuric acid solution (or $30 \%$ sodium hydroxide solution) were used for $\mathrm{pH}$ regulation of water samples, followed by flocculation experiments, and then the determination of ammonia concentration. By processing and analyzing the experimental data, the results are shown in fig.5.

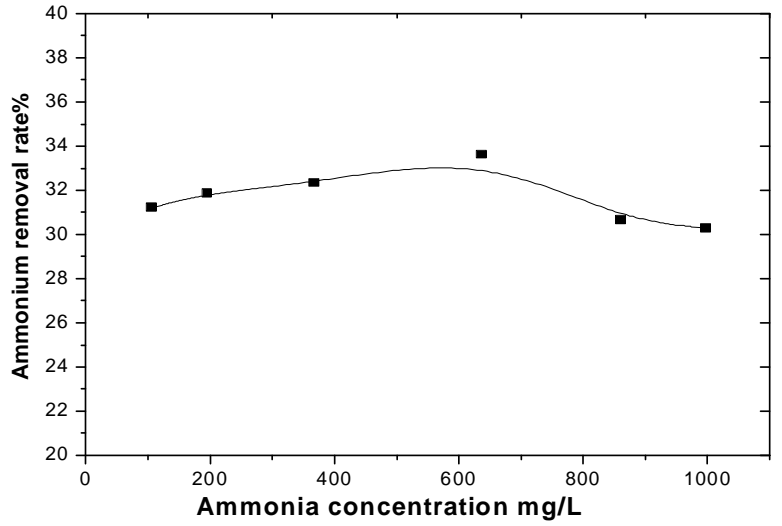

Fig.5 Effect of ammonia concentration on its removal rate

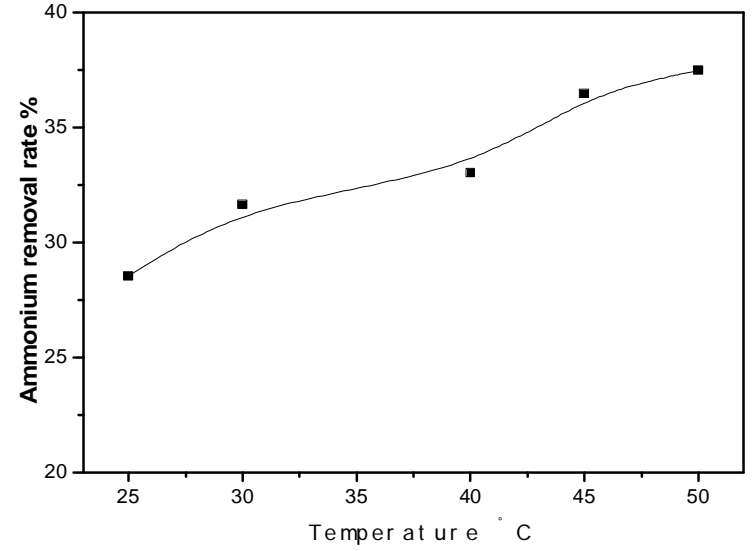

Fig.6 Effect of reaction temperature on ammonia removal rate

In the case of other conditions unchanged, the removal rate of ammonia nitrogen concentration from small to large, can be maintained between $30 \%$ to $35 \%$. It shows that the removal rate of ammonia nitrogen by iron carbon alloy micro filler is better, and it is not affected by the initial concentration of ammonia nitrogen. 
Effect of temperature on $\mathbf{N H}_{3}-\mathbf{N}$ removal: Preparation of ammonia nitrogen concentration was approximately $400 \mathrm{mg} / \mathrm{L}$ ammonium sulfate solution $500 \mathrm{ml}$ six copies, $30 \%$ sodium hydroxide solution to regulate $\mathrm{pH}$ was 7.0, then added to contain the quality than 1 iron carbon fillers six micro electrolysis device, then the six device placed at a temperature of $25{ }^{\circ} \mathrm{C}, 30{ }^{\circ} \mathrm{C}, 35^{\circ} \mathrm{C}, 40{ }^{\circ} \mathrm{C}, 45{ }^{\circ} \mathrm{C}, 50{ }^{\circ} \mathrm{C}$ water bath, respectively, and then continued aeration experiment. Immediately stop aeration when the residence time is $80 \mathrm{~min}$, and respectively from the device to remove $50 \mathrm{~mL}$ samples in six small beaker. Then the $30 \%$ sulfuric acid solution (or $30 \%$ sodium hydroxide solution) were used for $\mathrm{pH}$ regulation of water samples, followed by flocculation experiments, and then the determination of ammonia concentration. By processing and analyzing the experimental data, the results are shown in fig.6.

In the investigated temperature range, temperature increase of micro electrolysis and the ammonia nitrogen removal efficiency has improved to some extent, from 25 to $50{ }^{\circ} \mathrm{C}$, ammonia nitrogen removal rate increased from $28 \%$ to $37 \%$, temperature have a certain impact on the micro electrolysis treatment of ammonia, high temperature has conducive to the micro electrolysis of ammonia nitrogen removal.

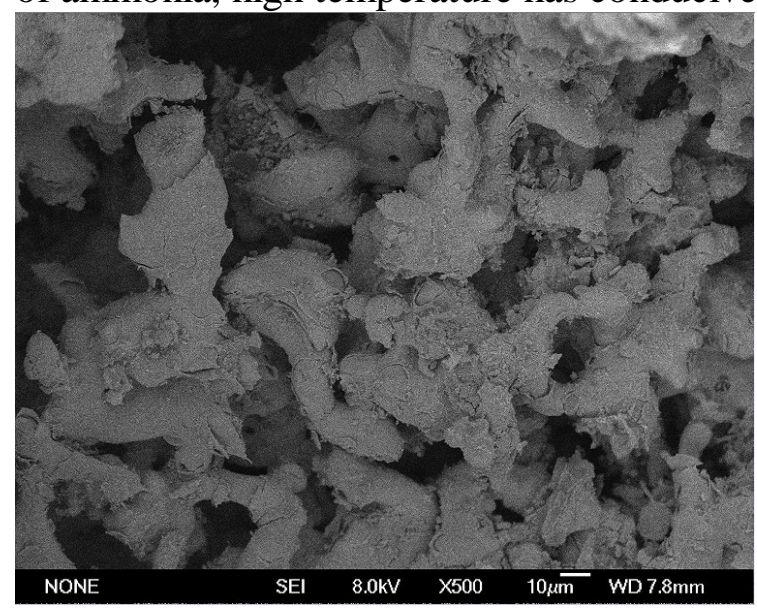

Fig.7. SEM photograph of fillers before and after

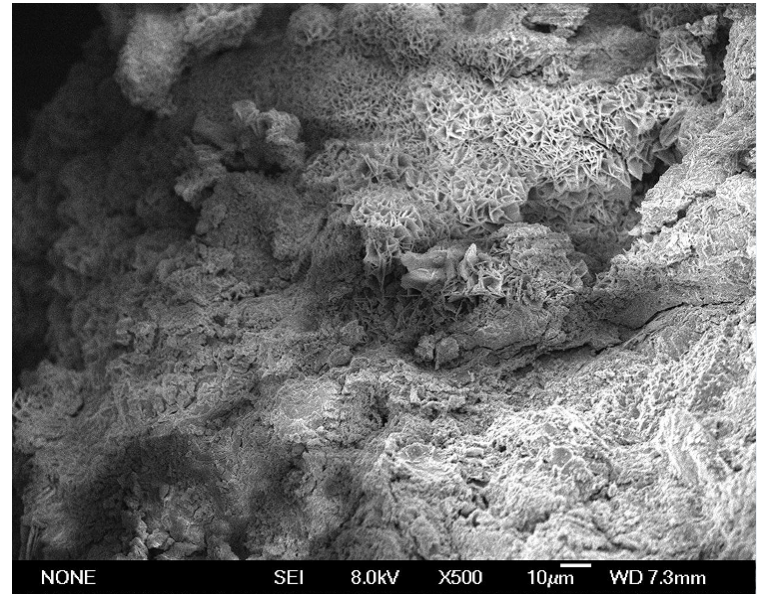

reaction

SEM photograph: The SEM photograph shows that the filler was a porous material with rough surface (Fig.7), the specific surface area was measured for $1.1 \mathrm{~m}^{2} / \mathrm{g}$ through the method of nitrogen adsorption, also numbers of the cavity can improve electron transfer efficiency and increase the electron pairs of the micro electrolysis process[8,9]. The larger specific surface area and large number of cavity make the electric adsorption to be possible, therefore the filler has a strong adsorption of $\mathrm{NH}_{4}{ }^{+}$and other ions. Observe the surface of the adsorbed filler, cavity inside were almost completely covered, attached to the surface was many fold crystals, obviously, these crystalline substance was salts crystal by these ions.

\section{Conclusions}

The novel iron carbon micro electrolysis filler in this study had better removal effect on $\mathrm{NH}_{3}-\mathrm{N}$ in wastewater. Removal pathways include flocculation and adsorption, but the main way is electric adsorption caused by micro electrolysis and the adsorption of filler itself. SEM photograph revealed that there were a lot of cavities in the interior of the filler, making the formation of micro electric field easy. Also the irregular surface causes the appearing of fold crystals.

Under laboratory conditions, the preparation of a certain concentration of solution $\left(\mathrm{NH}_{4}\right)_{2} \mathrm{SO} 4$ to simulate the ammonia nitrogen wastewater by experimental study, experimental results show that, the iron carbon alloy filler of $\mathrm{NH}_{3}-\mathrm{N}$ also better removal effect, when the reaction time is $80 \mathrm{~min}$, the influent $\mathrm{pH}$ is 7 influent $\mathrm{NH}_{3}-\mathrm{N}$ concentration was $600 \mathrm{mg} / \mathrm{L}$, reaction temperature and degree of $45^{\circ} \mathrm{C}$ and $\mathrm{NH}_{3}-\mathrm{N}$ removal rate reached $35 \%$. 


\section{Acknowledgements}

This work was supported by the Shandong Province Natural Science Foundation (Effect of micro-electrolysis pretreatment of salt water on microbial activity) under Grant no.ZR2013EEL008.

\section{References}

[1] Dai Ge-lian, Jing Wei-wei, Cheng Ai-hua, et al. Research on Enhanced Active Sludge Process by Micro-electrolysis Method Removal of COD[J]. Environmental Science \& Technology, 2009, 32(6C): 309-312.

[2] Barrera-Diaz C, Urena-Nunez F, Campos E, et al. A combined electrochemical- irradiation treatment of highly colored and polluted industrial wastewater. Radiat PhysChem, 2003, 67 (5) 657-663

[3] S. Rengaraj, K.H. Yeon, S.Y. Kang, J.U. Lee, K.W. Kim, S.H. Moon, Studies on adsorptive removal of Co (II), Cr (III) and Ni (II) by IRN77 cation-exchange resin, J. Hazard. Mater. 92 (2002) 185-198.

[4] Mohana. N, Balasubramanian. N, Ahmed Basha. C. Electrochemical oxidation of textile wastewater and its reuse, J. Hazard. Mater. 147(2007) 644-651.

[5] H. Cheng, W. Xu, J. Liu, H. Wang. Pretreatment of wastewater from triazine manufacturing by coagulation electrolysis and internal microelectrolysis, J. Hazard. Mater. 146 (2007) 385-392.

[6] Y.Z. Jin, Y.F. Zhang, W. Li, Micro-electrolysis technology for industrial wastewater treatment, J. Environ. Sci. 15 (2003) 334-338.

[7] Jeane, M., De Freitas. Iron and its sensitive balance in the cell. Mutation Res. 475(2001), 153-159.

[8] P. Gao, X. Chen, F. Shen, G. Chen, Removal of chromium (VI) from wastewater by combined electro-coagulation electroflotation without a filter, Sep. Purif. Technol. 43 (2005) 117-123.

[9] X. Yang, Interior microelectrolysis oxidation of polyester wastewater and its treatment technology, J. Hazard. Mater. 169 (2009) 480-485. 